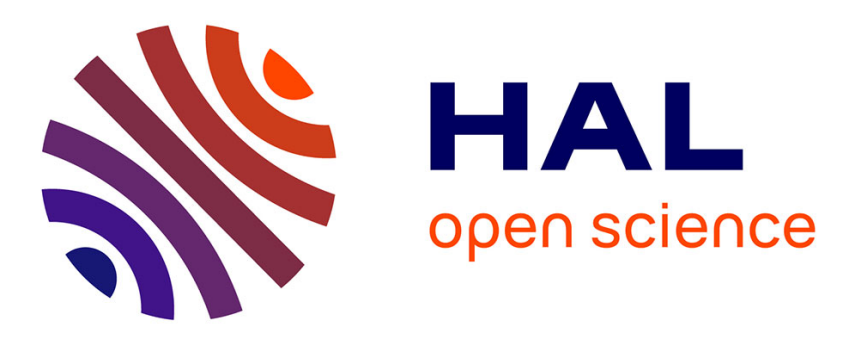

\title{
Anomalously low Rayleigh scattering by CdS/CdSe doped glasses
}

M. Shepilov, A Anan'Ev, L. Maksimov, A. Onushchenko, J. Margueritat

\section{To cite this version:}

M. Shepilov, A Anan'Ev, L. Maksimov, A. Onushchenko, J. Margueritat. Anomalously low Rayleigh scattering by CdS/CdSe doped glasses. Journal of Non-Crystalline Solids, 2020, 544, pp.120234. 10.1016/j.jnoncrysol.2020.120234 . hal-02871349

\section{HAL Id: hal-02871349 https://hal.science/hal-02871349}

Submitted on 5 Nov 2020

HAL is a multi-disciplinary open access archive for the deposit and dissemination of scientific research documents, whether they are published or not. The documents may come from teaching and research institutions in France or abroad, or from public or private research centers.
L'archive ouverte pluridisciplinaire HAL, est destinée au dépôt et à la diffusion de documents scientifiques de niveau recherche, publiés ou non, émanant des établissements d'enseignement et de recherche français ou étrangers, des laboratoires publics ou privés. 


\title{
Anomalously low Rayleigh scattering by CdS/CdSe doped glasses
}

\author{
M. Shepilov ${ }^{\mathrm{a}, 1}$, A. Anan'ev ${ }^{\mathrm{a}}$, L. Maksimov $^{\mathrm{a}}$, A. Onushchenko ${ }^{\mathrm{b}}, \mathrm{J}_{\text {. Margueritat }}{ }^{\mathrm{c}}$ \\ ${ }^{a}$ Vavilov State Optical Institute, 192171 Saint Petersburg, Russia \\ ${ }^{\mathrm{b}}$ ITMO University, 199034 Saint Petersburg, Russia \\ ${ }^{\mathrm{c}}$ Laboratoire de Physico-Chimie des Matiriaux Lurninescents, Universitt Lyon I, F-69622 \\ Villeurbanne, France
}

\begin{abstract}
Light scattering (Raman, Rayleigh and Mandelshtam-Brillouin) and absorption of commercial color glasses (cut-off optical filters containing nanocrystals of ternary compounds $\mathrm{CdS}_{x} \mathrm{Se}_{1-x}$ ) are studied. It was found for the first time that the contribution of nanocrystals to the Rayleigh scattering is unprecedentedly low for some of these glasses. This conclusion is confirmed by estimation of nanocrystal size and volume fraction from low-frequency Raman scattering and absorbance spectroscopy for a chosen set of samples. Anomalously low Rayleigh scattering of nanocrystals is explained in terms of interference of light scattered by different nanocrystals (interparticle interference). The possibility of interparticle interference effects in the case of small volume fraction of nanocrystals is illustrated by computer simulation using the model of diffusion-limited phase transformation proposed earlier.
\end{abstract}

Keywords: Glass, CdS/CdSe nanocrystals, Light scattering, Landau-Placzek ratio, Interference effects, Computer simulation

\footnotetext{
${ }^{1}$ Corresponding author.

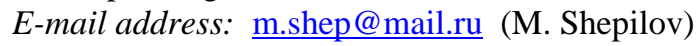




\section{Introduction}

Silicate glasses with CdS-CdSe nanocrystals (quantum dots) are being extensively studied during decades by a lot of structural sensitive methods such as absorbance and luminescence spectroscopy, transmission electron microscopy (TEM), small-angle X-ray scattering (SAXS), and the others [1-5].

Recently it was found that Rayleigh and Mandelshtam-Brilloun scattering (RMBS) spectroscopy can be effectively used for separating the contributions of nano-scaled fluctuation inhomogeneites of a glass host and semiconductor nanocrystals (NCs) into Rayleigh scattering intensity that opened a new path for estimating NCs number density in glasses [6].

In the present work, we apply RMBS spectroscopy to study of color glasses (optical cut-off filters) with $\mathrm{CdS}_{x} \mathrm{Se}_{1-x} \mathrm{NCs}$ and obtain an unexpected result: Rayleigh scattering intensity of some samples was practically as low as that for initial glasses without NCs. This result is discussed in terms of interparticle interference effects in scattering. To illustrate a possibility of interparticle interference in the case of small volume fraction of NCs, simulation of light scattering for a model system is carried out.

\section{Experimental}

\subsection{Glass samples}

Cut-off filter glasses of Russian production have been chosen for studying. Compositions of $\mathrm{ZhS}$ (yellow), OS (orange) and $\mathrm{KS}$ (red) glasses included $64 \mathrm{SiO}_{2}, 3 \mathrm{~B}_{2} \mathrm{O}_{3}, 13 \mathrm{ZnO}, 20\left(\mathrm{Na}_{2} \mathrm{O}+\mathrm{K}_{2} \mathrm{O}\right)$ (wt\%) while the concentration of dopants $(\mathrm{Cd}, \mathrm{S}$ and $\mathrm{Se})$ did not exceed $1 \mathrm{wt} \%$. As-melted glasses were colorless but their heat-treatment in the range $530-620^{\circ} \mathrm{C}$ induced their coloring. This effect is caused by precipitation of NCs and depends on both S/Se concentration ratio and heat-treatment conditions.

Glass samples of $15 \times 15 \times 10 \mathrm{~mm}^{3}$ dimensions with all polished faces were prepared for RMBS measurements. The same samples were studied by low frequency Raman scattering (LFRS) spectroscopy. Absorbance spectra were measured using plane-parallel plates with thickness of $0.1-0.25 \mathrm{~mm}$.

\subsection{Measurement procedures}

\subsubsection{RMBS spectroscopy}

RMBS spectra of the glass samples were taken by piezoelectric scanned Fabry-Perot interferometer. Light scattering was excited by He-Ne laser $(\lambda=633 \mathrm{~nm}$, power $\approx 35 \mathrm{~mW})$ and 
measured at the scattering angle $\theta=90^{\circ}$. To enhance contrast, the spectra were processed with Bayesian deconvolution technique. Spectral shifts of inelastic longitudinal (Mandel'shtamBrillouin) and transverse components of light scattering spectra, $\Delta v_{l}$, and $\Delta v_{t}$, and Landau-Placzek ratio $R_{\mathrm{L}-\mathrm{P}}=I_{\mathrm{R}} /\left(2 I_{\mathrm{MB}}\right)$, where $I_{\mathrm{R}}$ and $I_{\mathrm{MB}}$ are the intensities of elastic (Rayleigh) and Mandel'shtamBrillouin components, were measured within $\pm 0.5 \%, \pm 1 \%$ and $\pm(1-5) \%$, respectively. Using $I^{M B}$ as

an inner reference, $I^{R}$ may be estimated as a function of glass composition and external impact. Details of the measurement procedure can be found elsewhere $[7,8]$.

\subsubsection{Optical absorption}

Absorbance spectra of the glass samples were measured in $0.2-0.7 \mu \mathrm{m}$ spectral range by spectrophotometer Shimadzu UV 3600 using a round diaphragm of $2 \mathrm{~mm}$ diameter. High optical homogeneity of the samples was evidenced by coincidence of results of measurements carried out at different areas of a sample surface.

\subsubsection{LFRS spectroscopy}

The experiments were performed by means of LabRam HR equipped with super notches ensuring the resolution down to $7 \mathrm{~cm}^{-1}$. The spectra were obtained at $\lambda=532 \mathrm{~nm}$ with an $\mathrm{x} 50$ objective with a NA of 0.35 , at full power (100\%) using a confocal pinhole of $100 \mu \mathrm{m}$. Spectra taken at different scattering points of the samples were reproducible.

\subsubsection{Additional data}

Densities $\rho$, refractive indices $n$ and glass transition temperatures $T_{\mathrm{g}}$ of the glasses under study were taken from [9]

\section{Results}

\section{1. $R M B S$}

Typical RMBS spectra of as-melted and heat-treated glass ZhS 10 (I) are shown in Fig.1 where two doublets are caused by modulation of light wave by longitudinal (L) and transverse (T) hypersonic waves. The Rayleigh components (R) are surrounded by the ellipse, and their ordinates should be multiplied by 1000 .

The obtained RMBS spectroscopy data [spectral sifts of longitudinal (Mandel'shtam-Brillouin) and transverse components, $\Delta v_{l}$ and $\Delta v_{t}$, and Landau-Placzek ratio $\left.R_{\mathrm{L}-\mathrm{P}}\right]$ and some reference data of the glasses are summarized in Table 1. 


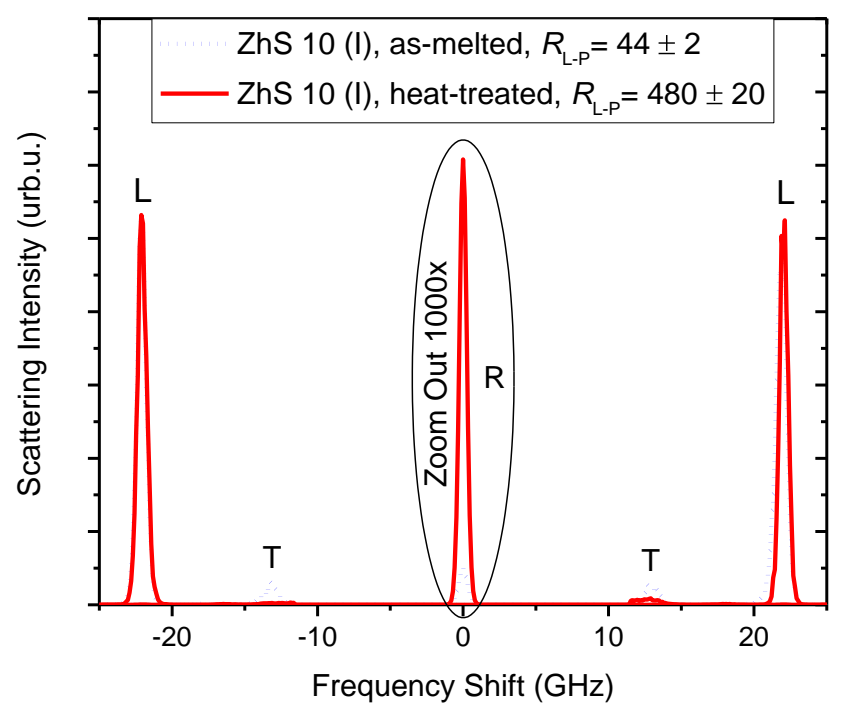

Fig. 1. RMBS spectra of $\mathrm{ZhS} 10$ (I) glass samples after deconvolution (256 iterations): as-melted (dots) and heat-treated (line). Scattering angle is $90^{\circ}, \mathrm{VV}+\mathrm{VH}$ polarization. Longitudinal (Mandelshtam-Brillouin), transverse and Rayleigh components are labeled by $\mathrm{L}, \mathrm{T}$ and $\mathrm{R}$, respectively.

\section{Table 1}

RMBS and reference data for some color filter glasses.

\begin{tabular}{|c|l|c|c|c|c|c|l|}
\hline$\#$ & \multicolumn{1}{|c|}{$\begin{array}{c}\text { Glass } \\
\text { code* }\end{array}$} & $R_{\mathrm{L}-\mathrm{P}}$ & $\begin{array}{c}\Delta v_{l} \\
\left(\mathrm{~cm}^{-1}\right)\end{array}$ & $\begin{array}{c}\Delta v_{t} \\
\left(\mathrm{~cm}^{-1}\right)\end{array}$ & $\begin{array}{c}\rho \\
\left(\mathrm{g} / \mathrm{cm}^{3}\right) \\
{[9]}\end{array}$ & $\begin{array}{c}n_{\mathrm{e}}\left(n_{\mathrm{D}}\right) \\
{[9]}\end{array}$ & Comments \\
\hline 1 & ZhS 10 (I) & $44 \pm 2$ & 0.630 & 0.373 & 2.64 & 1.525 & as-melted, colorless \\
\hline 2 & OS 23 (III) & $39 \pm 2-$ & 0.630 & 0.373 & - & - & as-melted, colorless \\
\hline 3 & KS 28 (I) & $37 \pm 2$ & 0.630 & 0.373 & - & - & as-melted, colorless \\
\hline 4 & ZhS 10 (I) & $480 \pm 20$ & 0.630 & 0.373 & 2.64 & 1.525 & heat-treated, yellow \\
\hline 5 & ZhS 11 (I) & $>1000$ & - & - & 2.64 & 1.525 & heat-treated, yellow \\
\hline 6 & ZhS 11 (II) & $320 \pm 10$ & 0.630 & 0.373 & 2.64 & 1.525 & heat-treated, yellow \\
\hline 7 & ZhS 12 (I) & $>1000$ & - & - & 2.64 & 1.525 & heat-treated, yellow \\
\hline 8 & ZhS 12 (II) & $>1000$ & - & - & 2.64 & 1.525 & heat-treated, yellow \\
\hline 9 & ZhS 16 (I) & $245 \pm 10$ & 0.630 & 0.373 & 2.64 & 1.525 & heat-treated, yellow \\
\hline 10 & ZhS 16 (II) & $48 \pm 2$ & 0.630 & 0.373 & 2.64 & 1.525 & heat-treated, yellow \\
\hline 11 & ZhS 17 (I) & $41 \pm 2$ & 0.630 & 0.373 & 2.64 & 1.525 & heat-treated, yellow \\
\hline 12 & ZhS 17 (II) & $83 \pm 4$ & 0.630 & 0.373 & 2.64 & 1.525 & heat-treated, yellow \\
\hline 13 & ZhS 18 (I) & $58 \pm 3$ & 0.630 & 0.373 & 2.64 & 1.525 & heat-treated, yellow \\
\hline
\end{tabular}




\begin{tabular}{|c|l|c|l|l|c|c|l|}
\hline 14 & ZhS 18 (II) & $116 \pm 5$ & 0.630 & 0.373 & 2.64 & 1.525 & heat-treated, yellow \\
\hline 15 & OS 11 (II) & $400 \pm 20$ & 0.630 & 0.373 & 2.64 & 1.525 & heat-treated, orange \\
\hline 16 & OS 12 (II) & $300 \pm 15$ & 0.630 & 0.373 & 2.64 & 1.525 & heat-treated, orange \\
\hline 17 & OS 13 (I) & $160 \pm 8$ & 0.630 & 0.373 & 2.64 & 1.528 & heat-treated, orange \\
\hline 18 & OS 13 (II) & $590 \pm 30$ & 0.630 & 0.373 & 2.64 & 1.528 & heat-treated, orange \\
\hline 19 & OS 14 (II) & $71 \pm 3$ & 0.630 & 0.373 & 2.64 & $(1.523)$ & heat-treated, orange \\
\hline 20 & KS 11 (II) & $>1000$ & - & - & 2.64 & - & heat-treated, red \\
\hline 21 & KS 13 (II) & $>1000$ & - & - & 2.64 & - & heat-treated, red \\
\hline
\end{tabular}

* Glasses of various batches are marked by (I)-(III).

Table 1 shows that as-melted (colorless) glasses are characterized by low values of LandauPlaczek ratio, $R_{\mathrm{L}-\mathrm{P}} \approx 40$. The low $\mathrm{R}_{\mathrm{L}-\mathrm{P}}$ values of colorless glasses are typical for cron glasses which have the composition close to that of the glasses under consideration. It is known that Rayleigh scattering by glasses is caused by fluctuations of density, anisotropy, and concentration in glass melt "frozen-in" at its cooling [10]. In the case of multicomponent silicate optical glasses, Rayleigh scattering intensity is mainly originated from "frozen-in" concentration fluctuations [11].

Heat-treatment does not affect the spectral shifts, the density, and the refractive index, but leads to coloring the glasses from yellow to red (Table 1) which is caused by precipitation of $\mathrm{CdS}_{x} \mathrm{Se}_{1-x}$ NCs (see below). Even if the volume fraction of NCs is very small $\left(\approx 10^{-4}\right)$, their precipitation should lead to a significant increase in the intensity of Rayleigh scattering whereas the intensity of Mandel'shtam-Brillouin scattering remains unchanged [6]. Hence, the precipitation of NCs should cause significant increase in Landau-Placzek ratio. For example, Landau-Placzek ratio of glasses with $\mathrm{CdS}$ or $\mathrm{CdSe} \mathrm{NCs}$ of $1.3 \mathrm{~nm}$ radius and volume fraction of 0.001 was estimated by equations of [6] as $R_{L-P}>1000$.

For some heat-treated glasses presented in Table 1, this conclusion is confirmed by experimental data (e.g., for color glasses \#5, \#7, and \#8, $R_{\mathrm{L}-\mathrm{P}}>1000$ ). However, for most heattreated color glasses in Table 1, Landau-Placzek ratio is significantly smaller, $R_{\mathrm{L}-\mathrm{P}} \wedge 300$, and, for two of them (\#10: ZhS16(II) and \#11: ZhS17(I)), this ratio is close to that of the as-melted colorless glass.

Thus, the data of Table 1 show that Rayleigh scattering of a system of NCs may be suppressed. To understand a degree of such suppression, we studied manifestation of NCs in optical absorption and LFRS. Using these methods, we estimated size and volume fraction of NCs for a number of the glasses, calculated Landau-Placzek ratio associated with Rayleigh scattering by NCs and compared the results of calculation with experimental data. 


\subsection{Optical absorption}

Examples of absorption spectra of the glasses are illustrated in Fig. 2. The absorption of the asmelted glass \#1 (ZhS10(I)) is negligible at wavelengths $\lambda>350 \mathrm{~nm}$. Heat-treatment shifts absorption edge to longer wavelengths, so that intensive absorption bands appear in visible spectral range. These bands in 250-450 nm spectral range can be explained by precipitation of $\mathrm{CdS}_{x} \mathrm{Se}_{1-x}$ NCs in a glass host (curves 2-5) while the absence of the bands in the spectrum of as-melted Zh10(I) glass evidences the absence of any crystal inclusions (curve 1) [12].

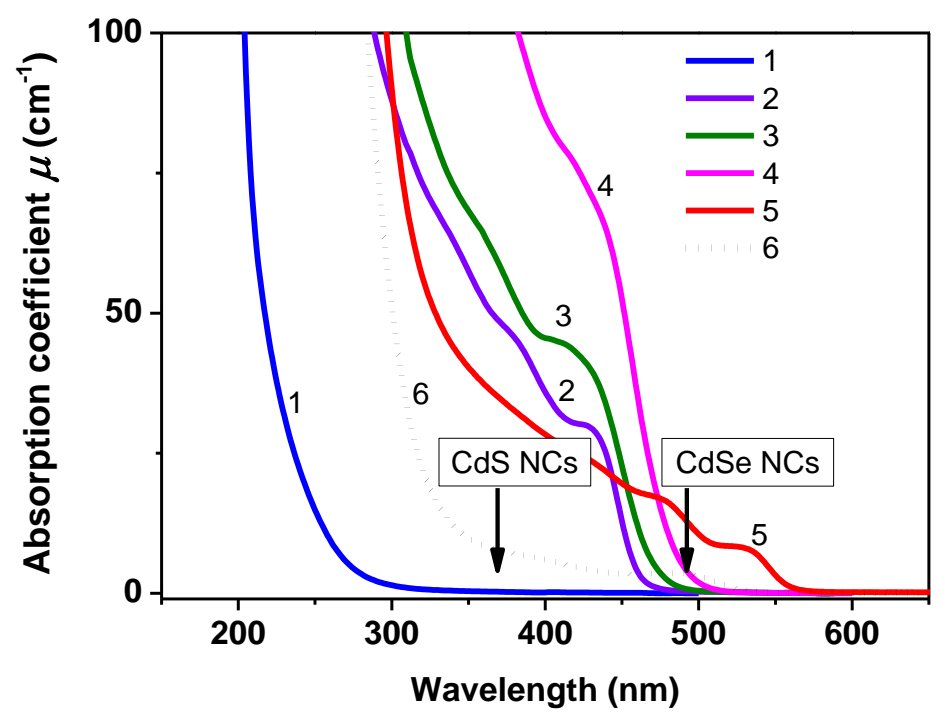

Fig. 2. Absorption spectra of the glasses: 1 - ZhS10(I), as-melted; 2 - ZhS16(I); 3 - ZhS17(I); 4 -

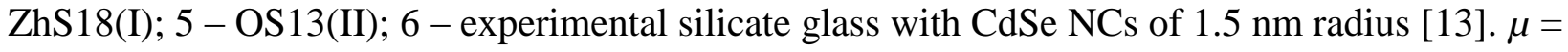
$-\log _{10}(\tau) / d$, where $\tau$ is internal transmittance, $d$ is sample thickness in $\mathrm{cm}$. The arrows show the wavelengths of the maxima of the lowest (in energy) absorption bands for CdSe doped glass (curve 6) and for silicate glass with CdS NCs of $1.4 \mathrm{~nm}$ radius [14].

Obviously, only CdSe NCs with a radius less than $1.5 \mathrm{~nm}$ could give absorption spectra similar to those presented by curves 2-4 in Figure 2. However, the glasses contain sulfur as well and its content is higher than the content of selenium. Therefore one can expect that radii of $\mathrm{CdS}_{x} \mathrm{Se}_{1-x} \mathrm{NCs}$ in these samples should be larger than $1.4 \mathrm{~nm}$.

As stated above, it should result in very large values of $R_{\mathrm{L}-\mathrm{P}}$ for the volume fraction of the crystalline phase appropriate for such glasses. To compare quantitatively experimental values of $R_{L-}$ ${ }_{P}$ ratios with those obtained within a simple model of independent Rayleigh scatters [6] one need getting values of NCs size and their volume fraction primarily. These data will be given below.

Absorption spectra of glasses of the same code but taken from various batches are shown in Fig.3. As one can see, they differ noticeably in the whole but coincide well only at $\mu$ values less 
than $6 \mathrm{~cm}^{-1}$ that corresponds to optical density 3 for the usual filter thicknesses of $5 \mathrm{~mm}$. Thus, being similar functionally samples of different batches may differ in parameters such as composition, volume fraction and/or size of NCs precipitated due to heat-treatment.
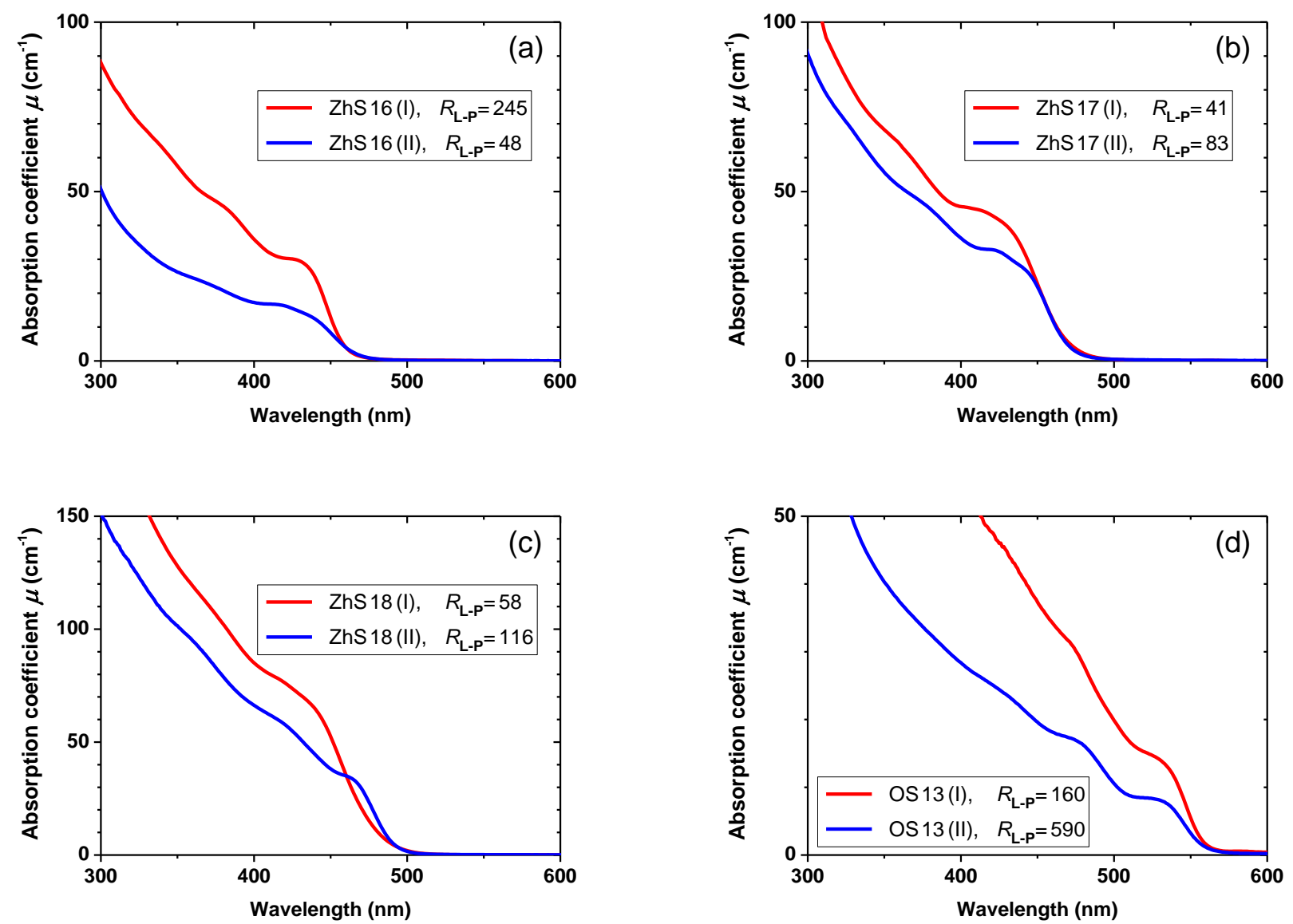

Fig. 3. Absorption spectra for glass samples of the same code taken from different batches.

These parameters though to a different extent may affect Rayleigh scattering intensity. However, there is no obvious correlation between the spectra and the measured values of $R_{\mathrm{L}-\mathrm{P}}$ for them (given in Fig. 3). Actually, absorption coefficients being proportional to the volume fraction of $\mathrm{CdS}_{x} \mathrm{Se}_{1-x} \mathrm{NCs}$ is larger for samples of the batch (I) whereas $R_{L-P}$ is larger for ZhS16(I) glass only. Moreover, the $R_{\mathrm{L}-\mathrm{P}}$ value for OS13(I) is more than three times lower than that of OS13(II) and it looks especially strange because the second derivative of their absorption spectra is quite similar evidencing the same composition and size of the precipitated NCs.

As to ZhS17 and ZhS18 glasses, some spectral shift to shorter wavelengths observed for samples of batch (II) can be due to a change of NCs composition but not due to a decrease of their size. In any case, extremely small values of $R_{\mathrm{L}-\mathrm{P}}$ for these glasses unambiguously cannot be explained with a simple model of independent Rayleigh scatters. The results give an additional hint for the existence of another factor governing Rayleigh scattering intensity strongly. 


\section{3. $L F R S$}

Having in mind the qualitative estimations of NC dimensions in Section 3.2 one can use the data of LFRS for determination of $\mathrm{CdS}_{x} \mathrm{Se}_{1-x} \mathrm{NC}$ size in the commercial filter glasses under study. Appropriateness and reliability of this technique applied to glasses with NCs, namely, $\mathrm{CdS}_{x} \mathrm{Se}_{1-x}$ was confirmed earlier by results of a lot of studies $[1,4,15,16]$.

Using formalism of [15], radius $a$ of NCs can be estimated as

$$
v_{\mathrm{LFRS}}=0.9 \mathrm{v}_{\mathrm{NCl}} /(2 a c)
$$

where $v_{\text {LFRS }}$ is the frequency of LFRS peak, $v_{\mathrm{NCl}}$ is the longitudinal sound velocity in precipitated $\mathrm{NCs}$ and $c$ is the light velocity in vacuum.

Normalized spectra of the ratio of scattered light intensity in polarized Raman spectra (VV) to the intensity in unpolarized ones (VH) for a selected set of samples are presented in Fig. 4.

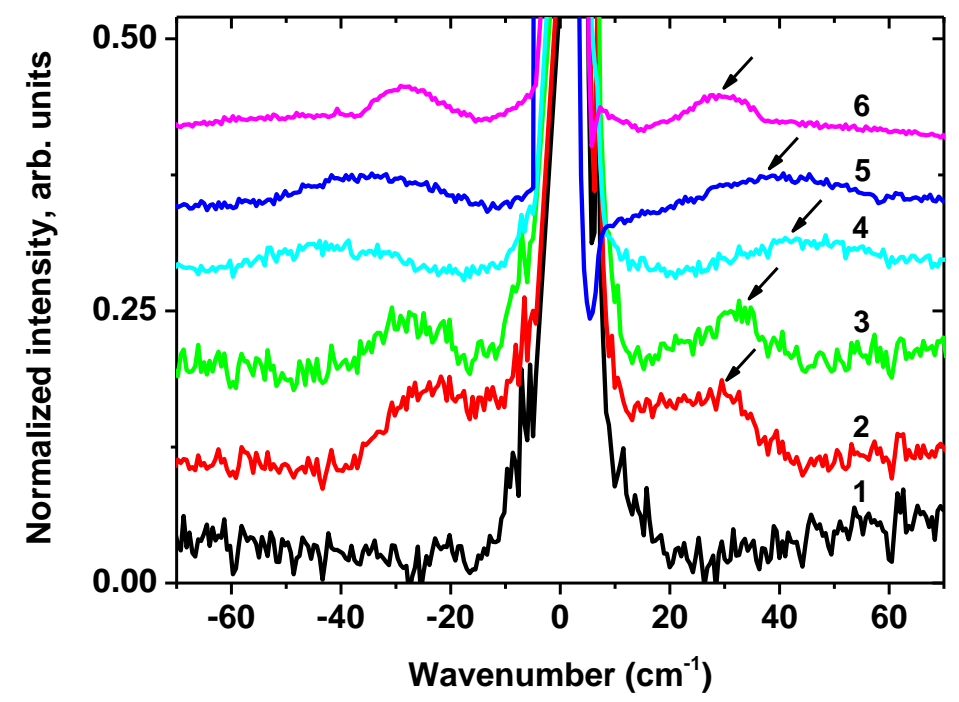

Fig. 4. Normalized LFRS spectra (VV/VH) for the glasses: 1 - ZhS10(I), as-melted; 2 - ZhS10(I?); 3 - ZhS16(I); 4 - ZhS17(I); 5 - ZhS18(I); 6 - OS13(II).

Fig.4 illustrates the absence of LFRS peak in the spectrum of as-melted glass and its appearance in the spectra after heart-treatments. Both intensity and position of the peak vary from one glass sample to another evidencing the change of NCs size. Lack of information about the composition and crystal modification of ternary compounds $\mathrm{CdS}_{x} \mathrm{Se}_{1-x}$ enforces to use the average values of longitudinal sound velocity in cubic and wurzite modifications $[17,18]$ :

$$
\mathrm{v}_{\mathrm{NCl}}=4300 \mathrm{~m} / \mathrm{s},(\mathrm{CdS})
$$




$$
\mathrm{v}_{\mathrm{NCl}}=3700 \mathrm{~m} / \mathrm{s},(\mathrm{CdSe}) .
$$

The data obtained for samples whose absorption spectra are given in Fig. 3 are summarized in Table 2.

\section{Table 2}

The frequencies of LFRS peaks, radii, and volume fractions of NCs.

\begin{tabular}{|c|c|c|c|c|c|}
\hline \multirow{2}{*}{ Glass code } & \multirow{2}{*}{$\begin{array}{c}v_{\text {LFRS }} \\
\left(\mathrm{cm}^{-1}\right)\end{array}$} & \multicolumn{2}{|c|}{ Radius $a(\mathrm{~nm})$} & \multicolumn{2}{c|}{$\begin{array}{c}\text { Volume fraction of } \\
\text { particles, } v_{\mathrm{f}}\end{array}$} \\
\cline { 4 - 7 } & & $\begin{array}{c}\text { for } \mathrm{v}_{\mathrm{NCl}} \text { of CdS, } \\
\text { Eq. }(2 \mathrm{a})\end{array}$ & $\begin{array}{c}\text { for } \mathrm{v}_{\mathrm{NCl}} \text { of CdSe, } \\
\text { Eq. }(2 \mathrm{~b})\end{array}$ & CdS & CdSe \\
\hline ZhS16(I) & $30.3 \pm 2.9$ & $2.13 \pm 0.2$ & $1.83 \pm 0.17$ & 0.0010 & 0.0008 \\
\hline ZhS17(I) & $41.4 \pm 0.6$ & $1.56 \pm 0.03$ & $1.34 \pm 0.02$ & 0.0015 & 0.0011 \\
\hline ZhS18(I) & $37.9 \pm 3.6$ & $1.70 \pm 0.17$ & $1.46 \pm 0.15$ & 0.0025 & 0.0019 \\
\hline OS13(II) & $28.4 \pm 0.6$ & $2.27 \pm 0.06$ & $1.95 \pm 0.05$ & 0.00105 & 0.00075 \\
\hline
\end{tabular}

To estimate volume fraction of nanocrystals, the absorption coefficient of glasses in 250-300 $\mathrm{nm}$ spectral range can be used under the assumption that deviations due to quantum confinement effects can be practically neglected [6]. For this estimation, extinction coefficients of CdS and CdSe NCs were calculated using the optical constants of bulk crystals for a number of wavelengths [19] and the expression for the efficiency of extinction of small particles (Eq. (5.7) in [20]). The calculations showed that the contribution of scattering in extinction (Eq. (5.8) in [20]) can be neglected in comparison with that of absorption in all variants presented below.

In the calculations, the radii of NCs were taken from Table 2 and their volume fractions were varied to obtain satisfactory agreement between the calculated and experimental values of extinction (absorption) coefficient of a given glass in the spectral range 250-300 $\mathrm{nm}$. The result of such fitting the volume fraction for the glass ZhS18(I) is shown in Fig. 5a. The estimated values of volume fractions are given in Table 2. To illustrate a degree of applicability of this procedure to volume fraction determination, we used it for the glasses containing CdSe NCs, for which volume fraction was measured independently by SAXS. The comparison of volume fraction values obtained by two methods (Fig. 5b) shows a satisfactory agreement of the results. 

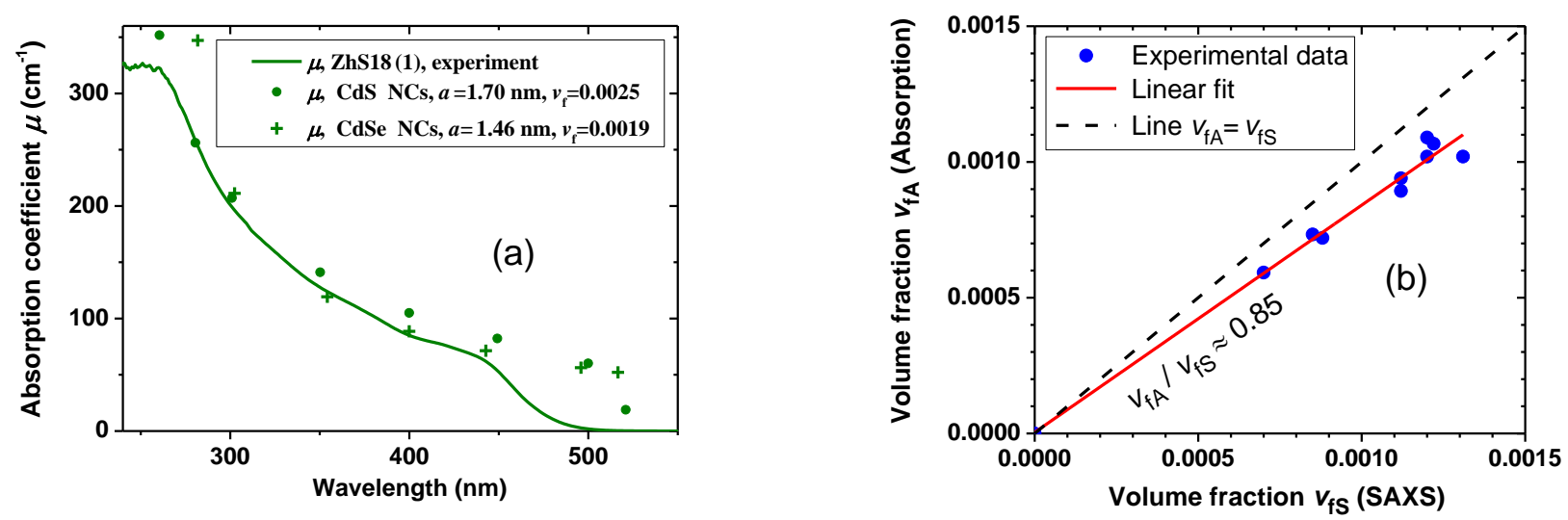

Fig. 5. (a): Absorption spectrum of the glass ZhS18(I) (line) and the values of absorption coefficient calculated for NCs of CdS (solid circles) and CdSe (crosses). (b): Volume fraction values found from absorption $\left(v_{\mathrm{fA}}\right)$ vs those determined by SAXS $\left(v_{\mathrm{fS}}\right)$ (solid circles) for glasses containing CdSe NCs and their linear fit by relation $v_{\mathrm{fA}} \approx 0.85 v_{\mathrm{fS}}$ (solid line).

\section{Discussion}

For a two-phase system consisting of NCs in a glassy matrix, Landau-Placzek ratio [6] is

$$
R_{\mathrm{L}-\mathrm{P}}=R_{\mathrm{L}-\mathrm{P}}^{\mathrm{h}}+R_{\mathrm{L}-\mathrm{P}}^{\mathrm{NC}},
$$

where $R_{\mathrm{L}-\mathrm{P}}^{\mathrm{h}}$ and $R_{\mathrm{L}-\mathrm{P}}^{\mathrm{NC}}$ are Landau-Placzek ratios of the glass host and contribution of NCs into $R_{\mathrm{L}-\mathrm{P}}$, respectively.

In the case of independent Rayleigh scattering of light by identical spherical NCs distributed randomly in a glassy host with a real refractive index $n$, the contribution of Ncs into the LandauPlaczek ratio $R_{\mathrm{L}-\mathrm{P}}$ can be written as [6]:

$$
R_{\mathrm{L}-\mathrm{P}}^{\mathrm{NC}}=\frac{I_{\mathrm{R}}^{\mathrm{NC}}}{2 I_{\mathrm{MB}}}=\frac{16 \pi^{2} N_{0} a^{6}}{n^{4} p_{12}^{2}\left(k T / \rho \mathrm{v}_{l}^{2}\right)}\left|\frac{m^{2}-1}{m^{2}+1}\right|^{2}=\frac{12 \pi v_{\mathrm{f}} a^{3}}{n^{4} p_{12}^{2}\left(k T / \rho \mathrm{v}_{l}^{2}\right)}\left|\frac{m^{2}-1}{m^{2}+1}\right|^{2}
$$

where $I_{\mathrm{R}}^{\mathrm{NC}}$ is the intensity of Rayleigh scattering by NCs; $N_{0}$ and $v_{\mathrm{f}}$ are number density and volume fraction of NCs; $p_{12}$ and $\mathrm{v}_{l}$ are Pockels coefficient and the hypersonic velocity of glass; and $T$ is the ambient temperature $(T=300 \mathrm{~K})$. Relative refraction index of NCs, $m=n_{\mathrm{NC}} / n$, is expressed in terms of their complex refractive index $n_{\mathrm{NC}}$ and the refractive index of glassy host $n$.

Hypersonic velocity $\mathrm{v}_{l}$ can be determined from the spectral sift $\Delta v_{l}$ of the longitudinal (Mandel'shtam-Brillouin) component by [10]

$$
\frac{\Delta v_{l}}{v}=2 n \frac{\mathrm{v}_{l}}{c} \sin \frac{\theta}{2}
$$

where $v$ is the frequency of exciting light, $\theta$ is the scattering angle. The obtained value of $\mathrm{v}_{l}$ is 5550 $\pm 40 \mathrm{~m} / \mathrm{s}$. The values of refractive indices of NCs at $\lambda=633 \mathrm{~nm}$ for evaluation of relative refractive 
indices $m$ in Eq. (3) are taken from [19]: $n_{p}=2.47(\mathrm{CdS})$ and $2.85+\mathrm{i} 0.32(\mathrm{CdSe})$. Finally, $p_{12}=-$ 0.22 taken for calculations of $R_{\mathrm{L}-\mathrm{P}}^{\mathrm{NC}}$ was found from comparison of RMBS spectrum of colorless as melted glass (See Table 1) and RMBS spectrum of commercial silica glass with $p_{12}=-0.28$ in accordance with [21]. Results of calculating $R_{\mathrm{L}-\mathrm{P}}^{\mathrm{NC}}$ are summarized in Table 3. Taking into account that the calculated values $R_{\mathrm{L}-\mathrm{P}}^{\mathrm{NC}}$ are significantly greater than $R_{\mathrm{L}-\mathrm{P}}^{\mathrm{h}}$, it is possible to adopt $\left(R_{\mathrm{L}-\mathrm{P}}\right)_{\text {calc }} \approx\left(R_{\mathrm{L}-\mathrm{P}}^{\mathrm{NC}}\right)_{\text {calc }}$. Using $I_{\mathrm{MB}}$ as an inner reference it seems easy to estimate the coefficient of Rayleigh scattering suppression, $I_{\mathrm{R}}(\exp ) / I_{\mathrm{R}}(\mathrm{cal})$.

Table 3

Concentration of nanocrystals, $\mathrm{N}_{0}$, and coefficient of Rayleigh scattering suppression $I_{\mathrm{R}}(\exp ) / I_{\mathrm{R}}(\mathrm{cal})$.

For CdS nanocrystals

\begin{tabular}{|l|l|l|l|l|}
\hline Glass Code & $\begin{array}{l}\mathrm{N}_{0} \\
\text { particle/cm }\end{array}$ & $\begin{array}{l}\mathrm{R}_{\mathrm{L}-\mathrm{P}} \mathrm{NP} \\
\mathrm{R}_{\mathrm{L}-\mathrm{P}} \text { cal }\end{array}$ & $\begin{array}{l}\mathrm{R}_{\mathrm{L}-\mathrm{P}} \\
\text { exp }\end{array}$ & $\mathrm{I}_{\text {exp }} / \mathrm{I}_{\text {cal }}$ \\
\hline ZhS16(I) & $26 \cdot 10^{15}$ & $(3.3 \pm 0.9) \cdot 10^{3}$ & $245 \pm 10$ & $\approx 7 \cdot 10^{-2}$ \\
\hline ZhS17(I) & $94 \cdot 10^{15}$ & $(2.0 \pm 0.1) \cdot 10^{3}$ & $41 \pm 2$ & $\approx 2 \cdot 10^{-2}$ \\
\hline ZhS18(I) & $122 \cdot 10^{15}$ & $(4.4 \pm 1.2) \cdot 10^{3}$ & $58 \pm 3$ & $\approx 1 \cdot 10^{-2}$ \\
\hline OS13(II) & $21 \cdot 10^{15}$ & $(4.4 \pm 0.4) \cdot 10^{3}$ & $590 \pm 30$ & $\approx 1 \cdot 10^{-1}$ \\
\hline
\end{tabular}

\section{For CdSe nanocrystals}

\begin{tabular}{|l|l|l|l|l|}
\hline Glass & $\begin{array}{l}\mathrm{N}_{0,} \\
\mathrm{QD} / \mathrm{cm}^{3}\end{array}$ & $\mathrm{R}_{\mathrm{L}-\mathrm{P}}^{\mathrm{QD}}$ cal $\approx$ & $\begin{array}{l}\mathrm{R}_{\mathrm{L}-\mathrm{P}} \\
\exp \end{array}$ & $\mathrm{I}_{\text {exp }} / \mathrm{I}_{\text {cal }}$ \\
\hline ZhS16(I) & $26 \cdot 10^{15}$ & $(3.1 \pm 0.8) \cdot 10^{3}$ & $245 \pm 10$ & $\approx 8 \cdot 10^{-2}$ \\
\hline ZhS17(I) & $109 \cdot 10^{15}$ & $(1.67 \pm 0.07) \cdot 10^{3}$ & $41 \pm 2$ & $\approx 3 \cdot 10^{-2}$ \\
\hline ZhS18(I) & $146 \cdot 10^{15}$ & $(3.7 \pm 1.1) \cdot 10^{3}$ & $58 \pm 3$ & $\approx 2 \cdot 10^{-2}$ \\
\hline OS13(II) & $24 \cdot 10^{15}$ & $(3.5 \pm .3) \cdot 10^{3}$ & $590 \pm 30$ & $\approx 2 \cdot 10^{-1}$ \\
\hline
\end{tabular}

Explanation for the effect of suppression of the Rayleigh scattering in glasses may be given on the basis of the approach where interference of light scattered by different elements of structure of nanostructured glass is considered [22]. In the case of NCs (or phase-separated particles) distributed in a glass matrix, two approaches are used for theoretical description of interference.

In the first approach, interference of light scattered by particle (NC) and its diffusion zone is considered [23]. The approach is applicable to early stage of particle growth when diffusion zones do not overlap. At certain conditions, such interference leads to suppression of dipole component in scattering, so that the intensity of scattering becomes significantly less than the intensity of the Rayleigh scattering by single particle. For randomly located zones (which are centered at randomly located particles), the theory of transformations predicts [24] that diffusion zones may be treated as 
isolated if their volume fraction is small, $v_{\mathrm{z}}<0.1$. Under this condition, particles grow independently and their volume fraction $v_{\mathrm{f}}$ is less than one tenth of volume fraction of particles in the end of growth stage, $v_{\max }$.

Let us estimate the maximum volume fraction of NCs in the glasses under consideration on the basis of batch composition. The glasses contain about 0.5 wt.\% of CdS. The simple estimation shows that this content corresponds to volume fraction $v_{\max } \approx 0.0027$. The letter value may be considered as the upper limit for precipitation of $\mathrm{CdS}$ phase because of evaporating sulfur during melting process and equilibrium solubility of $\mathrm{CdS}$ in the glass matrix. Thus, one can conclude that the volume fractions $v_{\mathrm{f}}$ presented in Table 2 are close to maximum volume $v_{\max }$, the condition $v_{\mathrm{f}}<$ $0.1 v_{\max }$ is not satisfied and the first approach is inapplicable.

In the second approach, interference of radiation scattered by different particles (NCs) is considered (interparticle interference) [25]. This approach was applied to small-angle X-ray (e.g., [26,27]) and light (e.g.,[22,28]) scattering in glasses. In this approach, it is assumed that the particles are distributed in homogeneous matrix. Thus, the approach is applicable to the stage of transformation when the active diffusional growth of particles from supersaturated solution is completed, the volume fraction of particles is close to maximum, and the concentration of precipitating component in the matrix is close to equilibrium. Basing on the estimate of volume fraction of NCs in the glasses under investigation, we consider that their structures are close to the structures accepted in the approach of interparticle interference. Below the interference effects will be analyzed in terms of this approach.

Interparticle interference was often observed in glass-ceramics with appreciable volume fraction of NCs, $v_{\mathrm{f}} \approx 0.1-0.4$ (for example, see $[26,29,30]$ ). The color glasses under consideration are classified as glass-ceramics [31]. However, the volume fraction of NCs in these glass-ceramics is very small, $v_{\mathrm{f}} \approx 0.001$ (Table 2 ), and it is usually assumed that such sparsely distributed NCs scatter the light independently without interference effects [32]. Nevertheless, the interparticle interference was observed in SAXS experiments for glasses containing small volume fraction $v_{\mathrm{f}} \approx$ 0.005 of NCs [27].

Because the notion of interparticle interference for sparsely distributed scatterers (NCs) contradicts the usually accepted opinion [32], it would be interesting to give any theoretical explanation for interparticle interference effects in a system with small volume fraction of scatterers. To give such an explanation, we use the model of phase transformation in a system with simultaneous nucleation of diffusional growth of NCs [33,34]. It should be noted that the conception of diffusion-limited growth of particles was used for explanation of interference effects in light scattering [Erreur ! Source du renvoi introuvable.], however, the authors of this work modeled two-dimensional case for significant area fraction 0.25 of two-dimensional particles. 
We consider the model $[33,34]$ where nuclei of a new phase are distributed in a glass matrix randomly with a mean number density $n_{0}$ and begin the diffusion-limited growth simultaneously. The model was proposed for description of transformation kinetics in a system with small supersaturation, in which the volume fraction of particles at the late stage of transformation is much less than unity. At the first stage (the growth stage), the particles (NCs) grow due to diffusion of precipitating component from supersaturated matrix and, as shown in [33], the possibility of Ostwald ripening can be neglected at this stage. Here we simulated the structure and light scattering of the system at time when the growth from supersaturated solution is completed, but effect of Ostwald ripening is not yet significant. As shown in [33,34], the distribution of volumes of particles at this time may be approximated by distribution of volumes of cells in the spatial Poisson-Voronoi tessellation [35]. Volume fraction of particles at this time is close to the maximum and remains practically constant during of the Ostwald ripening stage.

It should be noted that the results obtained in the model are in agreement with experimental data on metastable liquid-liquid phase separation in glasses [34]. The similar models were developed for the case of continuous nucleation [36,37].

As argued above, the volume fraction of NCs in the glasses under consideration is close to maximum. Hence, the stage of phase transformation in these glasses relates to the end of growth stage or to the Ostwald ripening stage. Our model gives the quantitative results only for the end of growth stage. Possibly, some conclusion may be qualitatively applied to the beginning of the Ostwald ripening stage.

Using the model, one can simulate the random location of particles (NCs) and calculate the volumes of cells of the spatial Poisson-Voronoi tessellation, that is, the diameters of particles at the end of growth stage if the particle volume fraction is given. Particles in the simulated system are polydisperse (e.g., see Fig. 5 in [34] and Fig. 6 below). If particles in our polydisperse system are sufficiently small and conditions of the Rayleigh scattering [20,38] are satisfied, the intensity of scattered light may be calculated by the equations derived earlier (Eqs. (16)-(19) in [38]). For calculation, particles are divided into size groups, and pair correlation functions for particles of different size groups (partial pair correlation functions) should be obtained in the course of simulation. Then partial structure factors and intensities of scattered light can be calculated for a given scattering vector. These calculations have been carried out in several series of computer experiments. Dimensionless representation of quantities was used. The volumes of simulated cubic samples were different in different series of computer experiments. To eliminate surface effects, particles belonging to surface layer of certain thickness did not used in calculation of particle radius distribution and partial pair correlation functions.

Let us present some results of the simulation. First of all, the distribution of dimensionless 
diameters $d=D /\langle D\rangle$ was simulated where $D$ and $\langle D\rangle$ are particle diameter and its mean value, respectively. The probability density $f(d)$ of the diameter distribution was estimated using the kernel method with the Gaussian kernel [39] and the window width (smoothing parameter) $h ; 0.006$ at which the mean integrated square error is minimum (Fig. 6). The statistical error of $f(d)$ is less than 0.005 and cannot be displayed in the scale of Fig. 6. The density $f(d)$ is almost symmetric with respect to $d=1$. It is practically equal to zero for $d<1.4$ and $d>1.6$. The density of distribution over 12 size groups is also shown in Fig. 6.

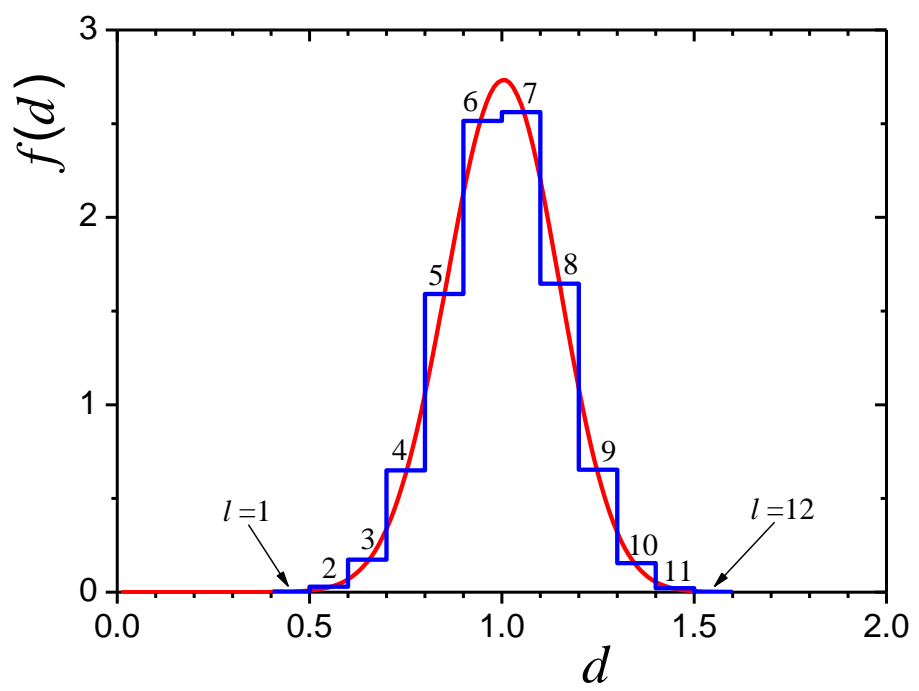

Fig. 6. The probability density $f(d)$ of the distribution of relative diameters $d=D /\langle D\rangle(\langle D\rangle$ is the mean diameter) (smooth curve) and the probability density corresponding to dividing particles into size groups $l(l=1,2, \ldots, 12)$ (stepwise line).

Partial pair correlation functions were simulated as functions of dimensionless distance $\rho=r n_{0}^{1 / 3}$ where $r$ and $n_{0}$ are the distance and the number density of particles (NCs) measured in dimensional units. Examples of simulated partial pair correlation functions for size groups 6 and 9 (see Fig. 6) are presented in Fig. 7. One can see that the pair correlation functions obtained in different series of numerical experiments coincide within statistical error. The simulated pair correlation functions indicate correlations in particle arrangement. First, the pair correlation functions are less than unity if $\rho^{\wedge} 1$, so that the probability of close spacing of particles is less than for random system where $g(\rho)=1$. Second, the pair correlation function in Fig. 7a shows maximum that means existence of preferred spacing between particles. The similar behavior takes place for the other simulated partial pair correlation functions. It should be noted that in monodisperse system these correlations in particle arrangement lead to significant interference 
effects in scattering [26].
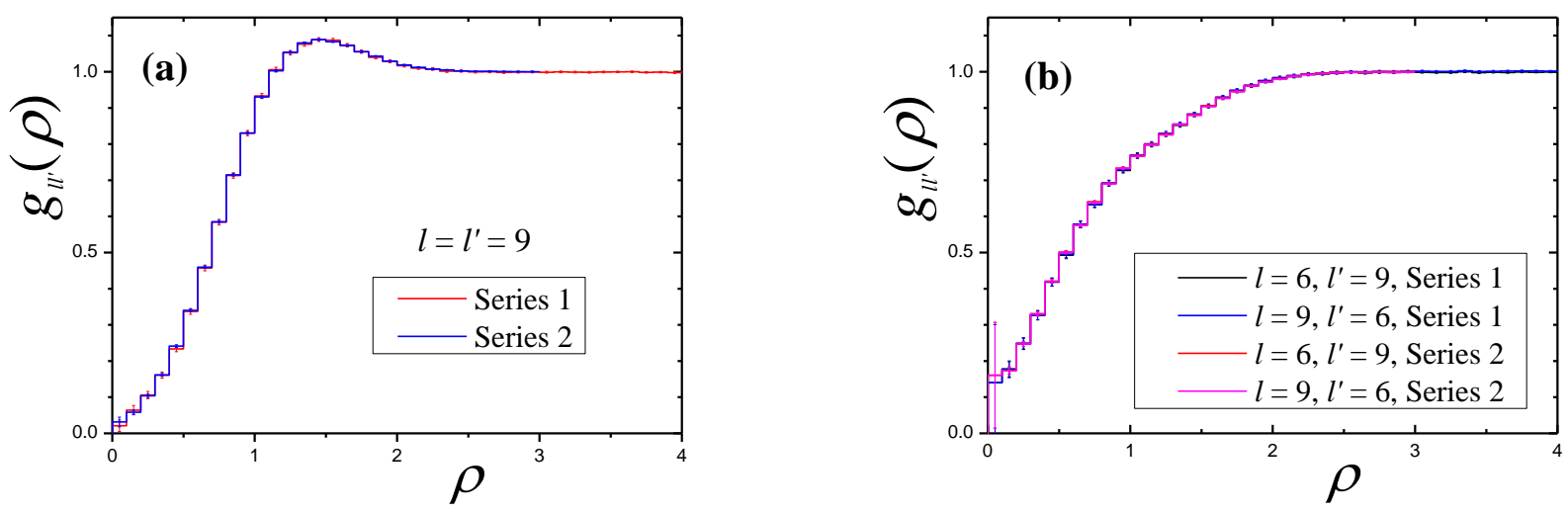

Fig. 7. Examples of simulated partial pair correlation functions $g_{l l^{\prime}}(\rho)$ (the results for two series of numerical experiments are shown).

The simulated partial PCFs $g_{l l}(\rho)$ were used for calculation of the partial structure factors $S_{l l^{\prime}}(\kappa)$ (see Eq. (18) in [38]) for a number of values of dimensionless scattering vector magnitude

$$
\kappa=4 \pi n \sin (\theta / 2) /\left(n_{0}^{1 / 3} \lambda\right)=(4 \pi)^{4 / 3} n \sin (\theta / 2)\left(3 v_{\mathrm{f}}\right)^{-1 / 3} a / \lambda
$$

where $\theta$ is the scattering angle.

The obtained values of the partial structure factors and Eq. (16) of Ref. [38] were used to evaluate the ratio $I_{\mathrm{sc}} / I_{\mathrm{sc}}^{\text {indep }}$ of scattering intensity for the simulated system, $I_{\mathrm{sc}}$, to intensity $I_{\mathrm{sc}}^{\text {indep }}$ of independent scattering by particles which have the same diameter distribution as in the simulated system (see Fig. 6). The calculated ratio $I_{\mathrm{sc}} / I_{\mathrm{sc}}^{\mathrm{indep}}$ is presented in Fig. 8 as a function of dimensionless scattering vector magnitude $\kappa$ for a number of series of computer experiments. 


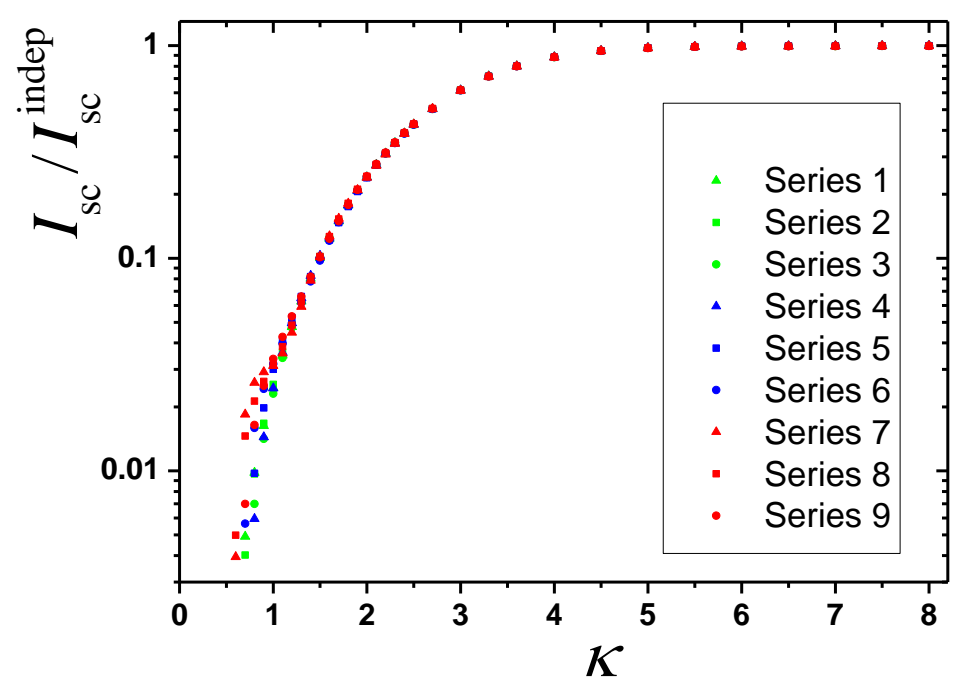

Fig. 8. The ratio of scattering intensities of for the simulated system, $I_{\mathrm{sc}}$, and the system of independent polydisperse scatterers, $I_{\mathrm{sc}}^{\text {indep }}$, as a function of dimensionless scattering vector magnitude $\kappa$.

Fig. 8 shows that the results obtained in different series of numerical experiments are in good agreement for $\kappa>1$. A greater difference among small values of $I_{\mathrm{sc}} / I_{\mathrm{sc}}^{\mathrm{indep}}$ at $\kappa^{\wedge} 1$ indicates that the current implementation of the model cannot ensure a high accuracy of the results at small values of $\kappa$. As possible reasons, one can mention the rough division of particles into size groups and the presentation of partial pair correlation functions as histograms.

The ratio of scattering intensities $I_{\mathrm{sc}} / I_{\mathrm{sc}}^{\text {indep }}$ is close to unity at $\kappa \% \mathrm{7}$, decreases with decreasing $\kappa$ and becomes less than 0.03 at $\kappa^{\wedge} 1$ (Fig. 8). This means that scattering should be low if the wavelength of light is large enough. This conclusion has a simple qualitative explanation. Indeed, in our model, the volume of a particle is proportional to the volume of its cell, i.e., the concentration of precipitated substance averaged over the cell is the same for all cells, and if the wavelength is much greater than the mean size of the cells (the interparticle distance), the light "sees" the material as almost homogeneous. In this case, the interference effects determine the scattering properties of the system.

Let us estimate values of dimensionless scattering vector magnitude $\kappa$ (Eq. (6)) for the experiments described above. Because volume fraction of particles is small (Table 2), the refractive index of the glass matrix is equal to that of the material, $n=1.525$ (Table 1 ). The scattering angle $\theta$ is equal to $90^{\circ}$. The wavelength is $\lambda=633 \mathrm{~nm}$. The number density $n_{0}$ (Table 3 ) was estimated using the equation $v_{\mathrm{f}} ; 4 \pi a^{3} n_{0} / 3$ where volume fraction $v_{\mathrm{f}}$ and radius $a$ of particles are taken from 
Table 2. As a result, the estimation gives the values $\kappa ; 0.6-1.0$. For such values, our model predicts the suppression of the scattering intensity in comparison with the case of independent scatterers by a factor of 30 and more. Such a situation is realized in glasses ZhS17(I) and ZhS18(I). However, in some other glasses the suppression is less. There are various reasons for different suppression of scattering. For example, different glasses may be characterized by somewhat different stages of phase transformation; in particular, different times of the Ostwald ripening stage may be realized. To discuss the situation in more detail, one needs more information on the thermal history and structure of glasses.

\section{Conclusions}

Main parameters of $\mathrm{CdS}_{x} \mathrm{Se}_{1-x}$ nanocrystals in glasses (radius, volume fraction, number density) can be determined by study of light scattering (Raman, Rayleigh and Mandelshtam-Brillouin) and absorption.

For the first time, it was observed that precipitation of $\mathrm{CdS}_{x} \mathrm{Se}_{1-x}$ nanocrystals in silicate glasses induced by their heat-treatment does not cause an appreciable increase in Rayleigh scattering intensity.

Anomalously low Rayleigh scattering of some glasses with $\mathrm{CdS}_{x} \mathrm{Se}_{1-x}$ nanocrystals has been explained in terms of interference of light scattered by different nanocrystals (interparticle interference). To illustrate that interparticle interference effects may be significant in in the case of small volume fraction of nanocrystals, computer simulation of structure and light scattering of a system of nanocrystals has been carried out using the model proposed earlier. In the model, the simultaneous nucleation and diffusion-limited growth of nanocrystals are considered. The structure of such a system was simulated at the stage when the diffusional growth from supersaturated solution is completed, but effect of Ostwald ripening is not yet significant. It was shown that in a long-wavelengths range the Rayleigh scattering by the system is suppressed due to interparticle interference effects even if the volume fraction of nanocrystals is small.

\section{Acknowledgements}

M.S. expresses his gratitude to the Russian Foundation for Basic Research (19-03-00855) for partial support of this work.

\section{References}

1. B. Champagnon, B. Andrianasolo, A. Ramos, M. Gandais, M. Allais, J.-P. Benoit, Size of $\mathrm{Cd}(\mathrm{S}, \mathrm{Se})$ quantum dots in glasses: Correlation between measurements by high-resolution 
transmission electron microscopy, small-angle $\mathrm{x}$-ray scattering, and low-frequency inelastic Raman scattering, J. Appl. Phys. 73 (1993) 2775-2780. https://doi.org/10.1063/1.353053.

2. B. Champagnon, M. Ferrari, B. Andrianasolo, E. Duval, CdSxSe1-x Nanocrystallites: New materials for non linear optics, Journal de Physique IV Colloque 01 (C7) (1991) C7-435-C7437. https://hal.archives-ouvertes.fr/jpa-00250765.

3. Y.M. Azhniuk, A.V. Gomonnai, Y.I. Hutych, V.V. Lopushansky, L.A. Prots, I.I. Turok, D.R.T. Zahn Evidence for formation of Se molecular clusters during precipitation of $\mathrm{CdSe}_{1-x} \mathrm{~S}_{x}$ nanoparticles in glass, Appl Phys A 95 (2009) 473-477. https://doi.org/10.1007/s00339-0084918-Z.

4. G. Irmer, J. Monecke, P. Verma, G. Goerigk, M. Herms, Size analysis of nanocrystals in semiconductor doped silicate glasses with anomalous small-angle $\mathrm{X}$ ray and Raman scattering, J. Appl. Phys. 88 (2000) 1873-1879. https://doi.org/10.1063/1.1305462.

5. M. Ivanda, K. Babocsi, C. Dem, M. Schmitt, M. Montagna, W. Kiefer, Low-wave-number Raman scattering from $\mathrm{CdS}_{x} \mathrm{Se}_{1-x}$ quantum dots embedded in a glass matrix, Phys. Rev. B 67 (2003) 235329. https://doi.org/10.1103/PhysRevB.67.235329.

6. M. Shepilov, A. Anan'ev, L. Maksimov, V. Savostyanov, V. Golubkov, P. Onushchenko, V. Ananyev, A. Onushchenko, Landau-Placzek ratio of an inorganic glass with PbS quantum dots, J. Non-Cryst. Solids 450 (2016) 156-163. http://dx.doi.org/10.1016/j.jnoncrysol.2016.08.011.

7. L. Maksimov, A. Anan'ev, Rayleigh and Brillouin scattering spectroscopy for oprical material science, in: M.C. Wythers (Ed.), Advances in Material Science Research, vol. 34, Nova Science Publishers Inc., New York, 2018, pp. 61-114. https://novapublishers.com/shop/advances-inmaterials-science-research-volume-34/.

8. A.V. Anan'ev, V.N. Bogdanov, B. Champagnon, M. Ferrari, G.O. Karapetyan, L.V. Maksimov, S.N. Smerdin, V.A. Solovyev, Origin of Rayleigh scattering and anomaly of elastic properties in vitreous and molten $\mathrm{GeO}_{2}$, J. Non-Cryst. Solids 354 (2008) 3049-3058. https://doi.org/10.1016/i.jnoncrysol.2007.12.008.

9. GOST 9411-91, Colored optical glass, Specifications, Moscow, 1991. (in Russian) http://gostexpert.ru/data/files/9411-91/4790ef60807e5c5995c012569f5e254a.pdf.

10. J. Schroeder, Light scattering of glass, in: M. Tomozawa, R.H. Doremus (Eds.), Treatise on materials science and technology, vol. 12, Academic Press, New York, 1977, pp. 157-222.

11. A.V. Anan'ev, V.A. Ananyev, V.N. Bogdanov, L.V. Maksimov, Characterization of optical glasses by Rayleigh and Mandel'shtam-Brillouin scattering and high temperature acoustic methods, Part 1, Flint glasses, Phys. Chem. Glasses: Eur. J. Glass Sci. Technol. B 56 (2015) 1523. http://www.ingentaconnect.com/content/sgt/ejgst/2015/00000056/00000001/art00003.

12. N.F. Borrelli, D.W. Hall, H.J. Holland, D.W. Smith, Quantum confinement effects of 
semiconducting microcrystallites in glass, J. Appl. Phys. 61 (1987) 5399-5409.

http://dx.doi.org/10.1063/1.338280.

13. V.V. Golubkov, P.A. Onushchenko, A.A. Onushchenko, The kinetics of the formation of CdSe nanocrystals in sodium-zinc-silica glass, Glass Phys. Chem. 40 (2014) 291-297. https://doi.org/10.1134/S1087659614030092.

14. A.I. Ekimov, A.A. Onushchenko, Size quantization of the electron energy spectrum in a microscopic semiconductor crystal, JETP 40 (1984) 1136-1139. http://www.jetpletters.ac.ru/ps/1259/article_19044.pdf.

15. E. Duval, A. Boukenter, B. Champagnon, Vibration eigenmodes and size of microcrystallites in glass: Observation by very-low-frequency Raman scattering, Phys. Rev. Lett. 56 (1986) 20522055. https://doi.org/10.1103/PhysRevLett.56.2052.

16. B. Champagnon, B. Andrianasolo, E. Duval. Nanocrystallites vibration modes of $\mathrm{CdS}_{x} \mathrm{Se}_{1-x}$ semiconductors in glasses: Size determination by Raman scattering, J. Chem. Phys. 94 (1991) 5237-5239. https://doi.org/10.1063/1.460529.

17. S. Adachi, Properties of group-IV, III-V and II-VI semiconductors, 2005.

18. S. Adachi, Properties of semiconductor alloys: group-IV, III-V and II-VI, 2009.

19. S. Adachi, Optical Constants of Crystalline and Amorphous Semiconductors, SpringerScience + Business Media, New York, 1999. http://dx.doi.org/10.1007/978-1-4615-5247-5.

20. C.F. Bohren, D.R. Huffman, Absorption and Scattering of Light by Small Particles, Wiley, New York, 1983, 2004.

21. A.I. Ritus, Method of Mandel'shtam-Brillouin scattering in quantum electronics and laser damage, Trudy FIAN, Nauka (Transactions of PN Lebedev Physical Institute, Academy of Science of USSR) 137 (1982) 3-190. (in Russian).

22. N.S. Andreev, Scattering of visible light by glasses undergoing phase separation and homogenization, J. Non-Cryst. Solids 30 (1978) 99-126. http://dx.doi.org/10.1016/00223093(78)90060-1.

23. M. Goldstein, Theory of scattering for diffusion-controlled phase separation, J. Appl. Phys. 34 (1963) 1928-1934. https://doi.org/10.1063/1.1729714.

24. J.V. Christian, The Theory of Transformation in Metals and Alloys, Part 1, Pergamon, An Imprint of Elsevier Science, 2002. Section 4.

25. A. Guinier, G. Fournet, Small-Angle Scattering of X-Rays, Wiley, N.-Y., 1955.

26. A.F. Wright, A.N. Fitch, J.B. Hayter, B.E.F. Fender, Nucleation and crystallization of cordierite- $\mathrm{TiO}_{2}$ glass ceramic: Part 1. Small angle neutron scattering measurements and simulations, Phys. Chem. Glasses 26 (4) (1985) 113-118.

27. I.P. Alekseeva, O.V. Atonen, V.V. Golubkov, A.A. Onushchenko, Morphology of Silicate 
Glasses with Lead Sulfide Nanocrystals, Glass Physics and Chemistry 33 (2007) 527-534. https://doi.org/10.1134/S1087659607060016.

28. M.P. Shepilov, On the problem of theoretical description of anomalous light scattering by phase separated glasses, Phys. Chem. Glasses 46 (2) (2005) 173-177.

http://www.ingentaconnect.com/content/sgt/pcg/2005/00000046/00000002/art00023.

29. M.P. Shepilov, O.S. Dymshits, V.V. Golubkov, A.A. Zhilin, Anomalously low light scattering in the $\mathrm{Na}_{2} \mathrm{O}-\mathrm{Nb}_{2} \mathrm{O}_{5}-\mathrm{SiO}_{2}$ glass-ceramics, Adv. Mater. Res. 39-40 (2008) 270-273. http://www.scientific.net/AMR.39-40.270.

30. M.P. Shepilov, O.S. Dymshits, A.A. Zhilin, V.V. Golubkov, A.E. Kalmykov, A.V. Myasoedov, A.A. Hubetsov, S.S. Zapalova, Effect of low $\mathrm{NiO}$ doping on anomalous light scattering in zinc aluminosilicate glass-ceramics, J. Non-Cryst. Solids 473 (2017) 152-169. http://dx.doi.org/10.1016/j.jnoncrysol.2017.08.012.

31. J. Deubener, M. Allix, M.J. Davis, A. Duran, T. Höche, T. Honma, T. Komatsu, S. Krüger, I. Mitra, R. Müller, S. Nakane, M.J. Pascual, J.W.P. Schmelzer, E.D. Zanotto, S. Zhou, Updated definition of glass-ceramics, J. Non-Cryst. Solids 501 (2018) 3-10. https://doi.org/10.1016/j.jnoncrysol.2018.01.033.

32. M.I. Mishchenko, L.D. Travis, A.A. Lacis, Scattering, Absorption, and Emission of Light by Small Particles (NASA, Cambridge University Press, Edinburgh, 2002). (see Ch. 3)

33. M.P. Shepilov, On some aspects of the calculation of phase separation kinetics in metastable solutions, Fiz. Khim. Stekla 17 (1991) 377-391. (in Russian).

34. M.P. Shepilov, Calculation of kinetics of metastable liquid-liquid phase separation for the model with simultaneous nucleation of particles, J. Non-Cryst. Solids 146 (1992) 1-25. https://doi.org/10.1016/S0022-3093(05)80472-7.

35. S.N. Chiu, D. Stoyan, W.S. Kendall, J. Mecke, Stochastic Geometry and its Applications, 3rd ed., Wiley, 2013. Section 9.7.3.

36. M.P. Shepilov, A model for calculation of isothermal kinetics of the nucleation-and-growth type phase separation in the course of one-step heat treatment, J. Non-Cryst. Solids 208 (1996) 64-80. https://doi.org/10.1016/S0022-3093(96)00499-1.

37. P. Bruna, D. Crespo, R. González-Cinca, E. Pineda, On the validity of Avrami formalism in primary crystallization, J. Appl. Phys. 100 (2006) 054907. (See Section II.A.) https://doi.org/10.1063/1.2337407.

38. M.P. Shepilov, Light scattering in optical material containing polydisperse spherical nanoparticles, Opt. Mater. 31 (2008) 385-390. http://dx.doi.org/10.1016/j.optmat.2008.05.012.

39. B.W. Silverman, Density Estimation for Statistics and Data Analysis, Chapman and Hall, London, 1986. 